\title{
Precursor de la ciencia moderna: infinito y unidad en el pensamiento de Giordano Bruno*
}

Modern Science Precursor: Infinity and Unity in the Thought of Giordano Bruno

Johan Bocanegra ${ }^{\dagger}$

\begin{abstract}
Resumen
La contribución de Giordano Bruno a la configuración de la Ciencia Moderna se analiza a la luz de sus escritos en contraste con el contexto en el que se desarrolló su obra. Este pensador italiano del comienzo del renacimiento es considerado uno de los precursores de la Ciencia Moderna. Este análisis se centra en comprender la relación entre dos conceptos en su visión del mundo: el infinito y la unidad. Se concluye que, aunque enuncia el concepto de espacio infinito y homogéneo su contribución no se puede rastrear fácilmente en el campo matemático, experimental o técnico, como es el caso de Galileo Galilei, aun así, los valores que impulsaron su búsqueda intelectual han penetrado la Ciencia Moderna a través del espíritu de curiosidad y el amor por el conocimiento y la investigación.
\end{abstract}

Palabras clave: epistemología de la ciencia - historia de la ciencia - ciencia moderna - renacimiento

\begin{abstract}
The contribution of Giordano Bruno to the configuration of modern science is analyzed in this article, based on his writes in contrast to the context in which his work was developed. This Italian thinker of the beginning of the renascence is considered one of the precursors of the modern science. My analysis is focused more on understanding the relationship between the two concepts in Bruno's world vision: the infinite and the unit. Although states the concept of infinite and homogeneous space his contribution is not traceable in a mathematical, experimental or technical field, like Galileo contribution is, the values that drive his intellectual searching has allowed all modern science goes through the curiosity spirit, love for knowledge and research.
\end{abstract}

Keywords: epistemology of science - history of science - modern science - renaissance

\footnotetext{
* Recibido: 28 de marzo de 2018. Aceptado con revisiones: 13 de febrero de 2019.

† Universidad Nacional de Colombia, Colombia. Para contactar al autor, por favor, escribir a: jabocanegrac@unal.edu.co. Metatheoria 10(1)(2019): 45-50. ISSN 1853-2322. eISSN 1853-2330.

(C) Editorial de la Universidad Nacional de Tres de Febrero.

(C) Editorial de la Universidad Nacional de Quilmes.

Publicado en la República Argentina.
} 


\title{
1. Introducción
}

\begin{abstract}
No es necesario, pues, investigar si fuera del cielo existe el lugar, el vacio o el tiempo, porque uno solo es el lugar general, uno el espacio inmenso que podemos llamar libremente vacio, en el cuál hay innumerables e infinitos globos, como este en el que vivimos y nos alimentamos nosotros. (Bruno 1584b, p. 175)
\end{abstract}

El presente artículo pretende mostrar la complejidad del pensamiento de uno de los personajes que se considera clave en los orígenes de la Ciencia Moderna: Giordano Bruno, quien vivió en Europa en el periodo comprendido entre los años 1548-1600. Por medio del análisis de algunos de sus textos se busca develar su aporte al desarrollo de la Ciencia Moderna y cómo, durante su momento histórico, se transforma y traslapa el pensamiento mágico y religioso con un pensamiento analítico, experimental y profundamente humanista; con seguridad estudiar el pensamiento de este autor en su propia obra devela aspectos claves de la historia de los orígenes de la Ciencia Moderna, principalmente por haber sido un pensador atrevido y haber logrado imaginar otros mundos posibles dentro de nuestro universo justo en un momento histórico en el que el control de la religión amenazaba el libre pensamiento por medio del uso de la fuerza excesiva. Revisando aspectos claves y profundos cómo el infinito y la unidad en su visión de mundo se reconocen los inicios del pensamiento racional y moderno en un contraste fascinante con los vestigios del pensamiento mágico medieval.

\section{Contexto de su obra}

Giordano Bruno nació en Nola, Italia, puede ser considerado como un pensador heterodoxo que se opuso a la visión aristotélica tradicional y privilegiada en su época. Sus ideas tienen influencia del neoplatonismo y el neopitagorismo (Hernández 2004, p. 33), él es considerado como el primer defensor de las teorías de Copérnico, sostuvo ideas radicales que lo llevaron a ser quemado por la inquisición, por el mismo inquisidor que años más tarde estaría tras el caso de Galileo. Bruno por lo general es mencionado como uno de los pensadores que aportó a la construcción de la Ciencia Moderna, pero en muchas ocasiones no se profundiza en sus ideas, ya que su pensamiento es complejo y abarca problemas epistemológicos, cosmológicos, religiosos e incluso mágicos (Hernández 2004, p. 80). Se mostrará un contexto que permita justipreciar su aporte a los orígenes de la Ciencia Moderna y entender en qué consistió la radicalidad de sus ideas. Escribió una serie de textos en latín y un conjunto de diálogos en italiano, mientras viajaba por Inglaterra bajo la protección de la embajada francesa (Yates 1964). Estos diálogos son variados, en ellos expone algunas de sus ideas, radicales frente a la postura y el contexto religioso; tanto para los académicos protestantes de Oxford, como para los católicos que querían atraparlo (al haber huido de la orden dominica de Nápoles 1576 tras ser acusado de herejía).

Bruno defiende la religión egipcia (Bruno 1990, p. 23, prólogo) desea regresar a la religión antigua, a la antigua sabiduría. Según Yates (1964) sobre Bruno ejerció una gran influencia el asclepius y las ediciones del corpus hermeticum dos libros que circulaban en su época, él fue atrevido y reinterpretó estos textos bajo una óptica no cristiana (tal vez motivado por una falsa datación del corpus que lo ubicaba en una época más antigua a la que hoy se acepta). Bruno fue sensible y tuvo una mente abierta, lo que le permitió ver e interpretar los signos: reconoció la enseñanza filosófica transmitida por los poetas como Ovidio en sus metamorfosis, (Bruno 1990, p. 26) leyó a Agripa, a Aristóteles, a Ficino, a Empédocles y Plotino (Bruno 1987b, pp. 75-80). Bruno fue un académico, un estudioso con formación eclesiástica, leyó los clásicos, decidió no seguir las corrientes de pensamiento privilegiadas en su época, y tuvo un amor por la sabiduría, por el conocimiento, muy grande, un gran furor para haber entregado su vida a la filosofía.

En este sentido es posible observar en el libro Sobre el infinito universo y los mundos (Bruno 1981, pp. 166-172) doce argumentos aristotélicos contra la posibilidad de la existencia de infinitos mundos que 
Bruno en voz de Filoteo debate uno a uno hábilmente, demostrando la posibilidad de los infinitos mundos en un único universo; es una de tantas muestras de su oposición a la corriente Aristotélica de la época que se oponía de base a la revolución Copernicana.

Parece que su actitud fue muy marcada y no bien recibida en Oxford, donde expuso sus teorías y defendió la óptica heliocéntrica del mundo con entusiasmo, tras su poca acogida (fue tomado como un verdadero demente) decidió escribir libros contra los doctos y académicos, destaca La cábala del caballo Pegaso, es decir el asno-burro, como símbolo de la ignorancia negativa: escepticismo e ignorancia positiva: camino a la verdadera filosofía (Bruno 1990, pp. 32-33). En esta obra se presenta una curiosa escena en la que un burro pide la entrada a una academia pitagórica, pero un mono lo rechaza, aun cuando este demuestra su gran aptitud (asinidad) para lograr hacerse discípulo y pese a la negativa del mico pitagórico el propio mercurio (Hermes) baja del cielo para dotar a este burro con el gran don de volverse académico. Son claras las relaciones con la tradición hermética al usar y analizar la imagen arquetípicas del asno (Bruno 1990, pp. 147-155).

\section{Su visión de mundo}

La visión de mundo de Bruno es compleja, y efectivamente se encamina en una búsqueda distinta a la de Galileo, pues Bruno antes de buscar comprobar de forma exquisita sus teorías por medios experimentales busca la unidad en el infinito. En su búsqueda pasa por el atomismo, y por las matemáticas, pero su principio, su causa, no puede ser reducida ni a un número ni a una figura. Parece ser que tal como Copérnico (Yates 1964, pp. 182-183), Bruno se vio influenciado por los Prisca Teologica de Ficino, texto donde se destaca la importancia del sol, y el movimiento de la tierra; esto entre otras cosas lo podría ubicar dentro de una corriente neopitagórica y neoplatónica propia del periodo del renacimiento, este estudio de las ideas clásicas alternativas a Aristóteles es evidente también en sus textos, en particular un bello dialogo en Mundo, magia memoria (Bruno 1987b, pp. 140149), al que haré referencia en este aparte del ensayo, en el que el Nolano en voz de uno de sus personajes lanza la siguiente pregunta:

¿Por qué Platón, a pesar de que vino después, no hizo ni lo mismo ni mejor que Pitágoras? La pregunta surge de la anterior exposición de Bruno, en la cual se contrasta la visión del átomo para Pitágoras como número, y para Platón como punto o forma, argumentando que la primera concepción es más pura. En este dialogo desarrolla la idea de que los números justifican las formas, más no en sentido contrario, del modo como la substancia extensiva, corpórea depende de la incorpórea. De modo que para entender y contemplar el principio indivisible (unidad) es más conveniente la aritmética que la geometría. Aun así en lo siguiente de su intervención ${ }^{1}$ explica cómo debemos pasar por el análisis de la multiplicidad para encontrar la unidad, y para esto hace unas construcciones geométricas explicativas, siguiendo métodos similares a los de Nicolás de Cusa, y aclara que la substancia y el ser son ajenos a la cantidad, la medida y el número y además la unidad no es número, pues esta es más bien su causa, en estos diálogos se hace evidente la complejidad de su búsqueda y su interés por la Filosofía Natural.

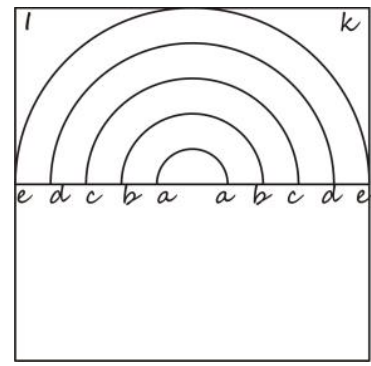

Figura 1. Precursor en el concepto de límite matemático al infinito Bruno(1987b) construye argumentos geométricos para sus ideas. A medida que el círculo se hace más grande se acerca más a la línea recta llegando a coincidir en el infinito.

${ }^{1}$ Filoteo, o Teófilo (amante de Dios), es por lo general el portavoz de sus teorías en los diálogos. 
La argumentación del pasaje citado pasa por un punto crucial para este ensayo, luego de analizar la figura 1: formada por varios arcos, secciones de círculos sucesivamente más grandes: el primer arco es un semicírculo con un pequeño radio en el centro de la figura entre los puntos aa, luego se observa un arco más grande tendido de $b$ hasta $b$, sucesivamente los arcos crecen conforme al radio, la curvatura va disminuyendo tendiendo al punto de tangencia entre el circulo y la recta superior $l k$, Bruno denota que llevando la sucesión de infinitos radios el círculo tienda a la recta, tal vez Bruno intuye las bases del cálculo infinitesimal, coincidiendo parcialmente con la visión que tendría Newton aproximadamente 120 años después. Sin algún rigor matemático Bruno muestra en el esquema como los arcos tienden a la recta, de ahí concluye que en los máximos y en los mínimos los contrarios se unifican y confunden, por esto en la figura se marca la recta con dos letras distintas $l y k$, los contrarios, mientras que en el arco las letras son la misma $a$ y $a$ pues hacen parte de una circunferencia, se unifican y se identifican entre sí, por lo tanto la recta $l k$ al provenir de un círculo máximo los contrarios $l$ y $k$ se confunden en una misma circunferencia máxima. Esto puede ser considerado como la esencia de su pensamiento "el infinito y la unidad son lo mismo, son como el universo, son su simulacro" (Bruno 1987b, p. 55): uno solo e infinito. ${ }^{2}$ Los contrarios solo se pueden separar por abstracción lógica, pues en realidad forman parte de un solo círculo infinito.

Aunque el heliocentrismo fue visto por Bruno como mathesis y jeroglífico, y los positivistas de la ciencia lo quisieron volver héroe de la ciencia positiva, sería muy escaso decir que este era el enfoque de su búsqueda. (Bruno 1987b, introducción) Para entender el problema planteado en este ensayo es quizá la mejor fuente el propio Bruno en su diálogo sobre la causa, principio y unidad, en el dialogo II (Bruno 1987b, pp. 63-89) declara que su tratamiento es un tratamiento de filósofo natural (Bruno 1987b, p. 64) aun cuando se cuestiona constantemente la idea de Dios en una óptica que hoy se denominaría teológica. En este dialogo expone que los átomos no son penetrables, no podemos conocer la materia por que las concreciones no son la materia, son en la materia. Y la forma es su entera compañera (Bruno 1987b, p. 85). La materia es la potencia, no es necesario que se imprima nada de fuera, además no hay otro universo. De aquí podemos entender que el espacio infinito esté por doquier lleno de modos animados. En su especulación habla de la existencia de conglomerados de materia semejantes al nuestro, y más aún de la posibilidad de la existencia de vida extraterrestre (en Bruno 1981, pp. 186-187); además cree que toda la materia está viva, todo está animado, todo tiene vida y principio vital, en particular los grandes animales: los planetas (Bruno 1987b, pp. 67, 78, Hernández 2004 , p. 28). Se puede ver como materializa al universo y animiza (e incluso intelectualiza) la materia, de modo que el universo es el gran talismán que actúa en la vía y contravía de la finitud en lo infinito. Es finito en dirección de la mínima e infinito en la máxima. Todos los cuerpos son concreciones de materia, compuesta por la Monada, el átomo o mínimo. La causa y el principio de un asunto difieren; la causa final del universo se reduce a ser en el instante en su multiplicidad, es decir a suscitar las múltiples formas. Mientras que la materia y la forma son los principios inseparables del mismo.

Bruno usa su gran conocimiento de la filosofía clásica para contra argumentar la física Aristotélica (no por el filosofó en sí mismo sino por la visión Medieval que se pretendía superar y se soportaba en estas teorías) con astucia construye su concepción del universo sobre el atomismo de Demócrito y la concepción del espacio Epicúreo, se enfoca en establecer fundamentos de no poca importancia para ver los verdaderos principios de la filosofía natural. Espacio, movimiento, materia, fuerza y potencia, son conceptos necesarios en sus diálogos y su concepción del mundo, de la physis, reta la concepción del movimiento en el que el movimiento necesita una causa última, un fin, y es regido por leyes de atracción entre lo semejante, según una clasificación de cuatro elementos y una quinta esencia sutil.

Es pertinente mencionar que Bruno planteó algo similar a un experimento imaginario dentro de su espacio infinito y supuso un escenario para desarrollar la gravedad aunque no llego a la misma, ni se tiene noticia de que haya influenciado directamente a Newton en su desarrollo, el Nolano imaginó como se movería una piedra entre dos planetas, "como la distancia local cambia la naturaleza del

\footnotetext{
2 En la teoría estándar actual de la astrofísica se plantea un modelo de universo finito, pero sin límites, Bruno afirma que el infinito lo es por carecer de límites, más no todo lo que carece de límites es infinito.
} 
cuerpo y cómo no, y porque puede suceder que al situarse una piedra a igual distancia entre dos tierras, o permanezca quieta o decida moverse hacia la una más bien que hacia la otra” (Bruno, 1981, p. 54), concluyendo que permanecerá quieta, si está equidistante a los planetas y no hay algo que la haga ir hacia uno más que hacia otro. Durante este dialogo Bruno rompe la cúpula de la tierra plana y los orbes como capas de una cebolla, y el espacio es tal que por él pueden moverse muchos astros, astros donde el abajo no es una dirección externa a ellos sino una dirección interna hacia su propio centro, y el arriba el cielo de cada tierra hacia el espacio infinito.

Todo esto permite conjeturar que la infinitud y la unidad son una necesidad dentro de su compleja filosofía, no se puede separar su cosmología de su magia ni de su arte de la memoria, aunque este ensayo no alcance a cubrir toda esta perspectiva, queda esbozada la profundidad de sus diálogos italianos.

\section{Algunas repercusiones de su pensamiento}

El aporte más relevante de Bruno como precursor de la ciencia moderna no reside en un constructo formal o un experimento propiamente dicho, pero si en una visión del universo donde antes que nada diferencio "universo" de "mundo" (planeta), y así logró imaginar sistemas solares con fuegos o soles y tierras o planetas que las orbitan todo dentro de la capacidad creadora de un universo con un espacio infinito donde la materia se regenera en cada instante de tiempo como en una respiración, un universo con infinitos mundos y la posibilidad de otros seres que los habiten, Bruno impulso la curiosidad por el espacio exterior, definió nuevamente el arriba y el abajo, e impulso una visión del cosmos donde el espacio es isotrópico, presentando los mismos principios naturales en cada lugar, sin privilegios, hoy en día consideramos esto cómo un axioma básico de la física moderna, la equivalencia entre las leyes físicas y entre los distintos observadores.

Los diálogos y la figura de este personaje han seguido estimulando a los pensadores durante estos cuatro siglos como se refiere por Rábade (1996). En particular es destacable la influencia de Bruno en el filósofo idealista alemán Schelling (1802), quien en su libro Bruno, o sobre el principio divino y natural de las cosas escribe a modo de diálogo en voz de Bruno una larga exposición sobre la unidad absoluta y el infinito de donde se toma este aparte sobre los planetas: ${ }^{3}$

Cuánto más tiene lo finito en un ser la naturaleza de lo infinito, [...] tanto más duradero y permanente [...] de esta naturaleza son los astros y los cuerpos celestes [...] (entendiendo su unidad) de la misma forma como a partir de la unidad absoluta la infinita multiplicidad de todas las cosas. Dado que cada cuerpo celeste no solo se esfuerza en reproducir en si todo el universo, sino que lo reproduce verdaderamente, son todos por cierto capaces, igual que un cuerpo orgánico, de infinitas transformaciones, pero en sí mismos son incorruptibles e inmortales (Schelling 1985, p. 68).

Como el gran escritor que fue Bruno reconoce la relación entre la literatura y la filosofía como se ve en Los heroicos furores ${ }^{4}$ (Bruno 1987a, p. 107), en este sentido no se podrá valorar justamente el aporte literario ni filosófico con este simple análisis pero puede representar el punto de partida para estimular la curiosidad por los textos escritos por este italiano.

\section{Conclusión}

Es posible conectar en Bruno toda una tradición hermética, mágica, alquímica de un alto grado de abstracción filosófica, y en concordancia con Eliade (1956) se puede concluir que la búsqueda del legado de los alquimistas, de los protocientíficos se debe buscar profundamente en los valores que promovieron y heredaron a la ciencia, en particular la curiosidad:

\footnotetext{
${ }^{3}$ Como curiosidad un cráter de la luna lleva su nombre, reencuentra en el límite con el lado oscuro.

${ }^{4}$ Bruno narra y luego interpreta una irónica historia en su obra, el ave Fénix y el Furioso se entregan juntos al fuego; Bruno se identifica con este Furioso y años más tarde termina en la hoguera.
} 
Queríamos simplemente demostrar que es su fe en la ciencia experimental y en sus grandiosos procesos industriales donde hemos de buscar la continuación de los sueños alquímicos. La alquimia ha legado al mundo moderno mucho más que una química rudimentaria: le ha transmitido su fe en la transmutación de la Naturaleza y su ambición de dominar el tiempo. (Eliade 1956, p. 154)

Así que el legado de Bruno no está en el campo de la técnica, ni aun de la matemática o de la geometría (como podría ser lógico con Galileo Galilei), su legado podría estar en la ambición de nuestra mente por rastrear el espacio ilimitado (infinito) con telescopios, naves y sondas; la fascinación por la existencia de otros mundos habitables, con otros seres de la misma materia y sometidos a la misma física que nosotros.

Aunque sus métodos son más bien filosóficos que científicos este pensador del renacimiento regala a la ciencia moderna una concepción de "espacio" homogéneo, isotrópico, infinito,, lugares similares sin privilegios aparentes con los mismos principios naturales, las mismas leyes, un vacío capaz de contener cuerpos, tierras, planetas, sistemas solares, esa increíble visión del cosmos daría paso con facilidad a la concepción Newtoniana del Universo un siglo después, así como con otras visiones modernas del mundo donde hay indiferencia del espacio y de la naturaleza, el hombre deja de ser especial respecto a otros seres, o todo pierde la divinidad o todo la gana, en Bruno parece predominar la segunda opción donde toda la materia es divina.

La coincidencia del infinito y la unidad, tanto en número como en forma, probablemente no sea justamente valorada ni en las ciencias ni en la matemática, tanto por su lenguaje poco técnico como por el eclipse que puede suponer los descubrimientos y experimentos de Galileo que configuraron efectivamente el origen de la ciencia moderna, sin embargo su pensamiento permitió transformar la visión del espacio que nos contiene en un espacio más potente, al ser capaz de albergar infinitos mundos, e incluso de auto contenerse: infinito y unidad.

El espíritu de Bruno habita y aún con más fuerza en el amor heroico que expresan todos los librepensadores que aceptan su ignorancia y no temen ser vistos como asnos, a quienes inspira la imagen que plasma en nuestra memoria aquel que murió en la hoguera por considerar la unidad y el infinito como objeto de discusión (Filosofía) y acción (Magia). Al no acceder a la experimentación no se puede considerar como un científico, pero si fue un precursor de los mismos y su historia está atada a los orígenes de la Ciencia Moderna. "El amor es aquello que mueve e impulsa al intelecto a fin de que éste lo preceda cual una linterna” (Bruno 1987a, p. 73).

\section{Bibliografía}

Bruno, G. ([1584a] 1981), Sobre el infinito universo y los mundos, Barcelona: Ediciones Orbis.

Bruno, G. ([1585a] 1987a), Los heroicos furores, Madrid: Tecnos.

Bruno, G. ([1584b] 1987b), Mundo, magia, memoria (selección de textos), Madrid: Taurus.

Bruno, G. ([1585a] 1990), Cábala del caballo Pegaso, Madrid: Alianza.

Cia, D. (2000), "La cena de las cenizas. Giordano Bruno", A Parte Rei: Revista de Filosofía 12: 1-4.

Eliade, M. ([1983] 1956), Herreros y alquimistas, Madrid: Alianza.

Hernández, C. (2004), Galileo Galilei: el arte de la ciencia, Bogotá: Universidad Nacional de Colombia/Colciencias/ Fundación Mazda.

Rábade, A. (1996), "La actualidad de Giordano Bruno en castellano”, Revista de Filosofia 9(15): 219-225.

Schelling, F. ([1802] 1985), Bruno o sobre el principio divino y natural de las cosas, Barcelona: Ediciones Orbis.

Yates, F. (1964), Giordano Bruno y la tradición hermética, Barcelona: Ariel. 